\title{
Hypofrontality revisited: a high resolution single photon emission computed tomography study in schizophrenia
}

Klaus P Ebmeier, Stephen M Lawrie, Douglas H R Blackwood, Eve C Johnstone, Guy M Goodwin

\begin{abstract}
Hypofrontality or reduced activity in the prefrontal cortex, measured as reduced frontal perfusion or glucose uptake, has gained the status of an established finding in the medical literature on schizophrenia. Many relevant studies, however, have potential sources of bias, such as small subject numbers, or unreliable performance of activation tasks by the patients during the scanning procedure. Seventy patients with non-affective and non-organic psychoses were recruitedmost qualifying for DSM III-R schizophrenia or schizophreniform psychosis (n = 60)-together with 20 healthy volunteers. They underwent single photon emission computed tomography with ${ }^{99 m}$ Tc-exametazime, carried out at rest. Tracer uptake was normalised to the occipital cortex. Group differences in tracer uptake were predicted in anterior regions of interest (prefrontal cortex and mesial frontal/cingulate cortex). Actively psychotic (including schizophrenic) patients not taking any drugs showed increased uptake in the prefrontal cortex. Reduced tracer uptake occurred in the mesial frontal cortex of schizophrenic patients, particularly if they were taking drugs. Relatively increased prefrontal tracer uptake associated with relatively decreased mesial frontal uptake characterised the patients in comparison with the controls. Generalised hypofrontality is, therefore, not a feature of schizophrenic patients at rest whether taking drugs or not.
\end{abstract}

MRC Brain

Metabolism Unit, Royal Edinburgh Hospital, Morningside Park, Edinburgh EH10 5HF, UK K P Ebmeier G M Goodwin University Department of Psychiatry, Royal Edinburgh Hospital, Morningside Park, Edinburgh EH10 5HF, UK

S M Lawrie

D H R Blackwood

E C Johnstone

Correspondence to:

Dr Klaus P Ebmeier.

Received 21 July 1994 and in revised form 24 November 1994

Accepted 2 December 1994 heterogeneity of patient samples. ${ }^{2}$ In fact, hypofrontality is typically reported in chronically ill patients treated with drugs, ${ }^{138}$ whereas several studies of patients with or without drug treatment have failed to replicate it. ${ }^{9-14}$ Drug naive acutely ill patients have even shown the opposite pattern-namely, increased frontal tracer uptake. ${ }^{15} 19$

The second conclusion that can be drawn from recent studies is that activation procedures increase the separation in frontal brain activity between control and schizophrenic groups $^{220}$ Some authors have argued that this is due to the task removing the variability that occurs during the uncontrolled resting state in patients ${ }^{20}$ and have redefined hypofrontality as "the inability to increase frontal blood flow in response to a frontal stimulus". ${ }^{2}$ It is doubtful, whether such a redefinition advances our understanding of schizophrenia. The poorer performance of "frontal" activation tasks by patients with schizophrenia is probably sufficient explanation for the difference from controls, who perform such tasks well. Activation hypofrontality may, therefore, tell us more about the functional topology of the task than about schizophrenia.

The emergence of lipophilic blood flow markers, such as technetium- $99 \mathrm{~m}$ labelled hexamethyl-propylenamine oxime (HMPAO, exametazime), has made it possible to examine large numbers of more representative psychiatric patients. Single photon emission computed tomography (SPECT) with ${ }^{99} \mathrm{Tc}$ exametazime provides a monotonic measure of regional cerebral blood flow that has been validated in animal and human studies. ${ }^{21-26}$ It reflects metabolic activation patterns during physiological, ${ }^{27} 28$ psychological, ${ }^{29}{ }^{30}$ and pharmacological ${ }^{31-33}$ activation experiments. Tracer activity can be measured reliably by normalising regional counts to a reference area such as the cerebellum, occipital cortex, or whole brain. ${ }^{34}$ By contrast with the nontomographic and tomographic methods involving xenon-133 inhalation, SPECT with 99m Tc-exametazime allows for high spatial resolution (up to $7 \mathrm{~mm}$ ) in deeper structures of the brain. This is relevant for the detailed examination of mesial cortical and subcortical grey areas. Most tomographic imaging studies have not distinguished further between frontolateral and mesial frontal cortex. Studies which make this distinction tend to report mesial frontal reductions in activity. ${ }^{2} 8161935-37$

In the present study we have examined four subgroups of psychotic patients and one control group with the hypothesis that by contrast 
with our actively psychotic, schizophrenic patients not taking drugs, ${ }^{19}$ more chronically ill schizophrenic patients treated with drugs would show a hypofrontal pattern of tracer uptake.

\section{Subjects and methods}

To be included in the first patient group, patients had to be actively psychotic at presentation to the Royal Edinburgh Hospital (to experience delusions, hallucinations, or display formal thought disorder). Patients meeting criteria for DSM-III-R diagnosis of major depressive or manic episodes were excluded. Patients were included if they were either neuroleptic naive, or if they had not received neuroleptics for at least two weeks for oral medication, or two months for intramuscular treatment. Nineteen patients qualified for DSM-III-R diagnosis of schizophrenia (15 paranoid, three disorganised, one undifferentiated), one patient for schizophreniform disorder, five as schizoaffective disorder, one paranoid disorder, one brief reactive psychosis, and two psychoses not otherwise specified. ${ }^{38}$ These drug free patients were treated as two groups, one consisting of 19 schizophrenic and a single schizophreniform patient, the other consisting of the remaining 10 schizoaffective and other psychoses. Data on the schizophrenic subgroup have previously been published. ${ }^{19}$ Table 1 lists details of these patients.

The second group consisted of 40 patients qualifying for DSM-III-R schizophrenia ( $=$ 38) or schizophreniform disorder $(n=2)$ (table 1). This group was selected from inpatients and outpatients at the Royal Edinburgh Hospital, specifically to include 20 patients with and 20 without a good treatment response. ${ }^{39}$ Patients were symptomatically assessed with the Manchester scale. ${ }^{40}$ Patients with a good treatment response were in remission or partial remission from symptoms, patients with a poor treatment response showed more symptoms. All were receiving neuroleptic drugs.

As a control group, we used the 20 youngest subjects of our control pool of healthy volunteers who have been recruited from community sources (table 1 ).

All subjects were examined with a single slice 12 detector scanner (SME-Multi X 810; Strichman, Medfield, MA, USA) with an in slice resolution of $7.5 \mathrm{~mm}$ (full width half maximum) at a slice thickness of $15 \mathrm{~mm}$ and a sensitivity measured as $520 \mathrm{c} / \mathrm{s}$ in a head sized phantom containing $1 \mathrm{kBq} / \mathrm{ml} .^{34}$ Intermediate resolution ( 572 hole) focusing collimators were used. Subjects underwent cannulation of an arm vein and were allowed to rest for about 15 minutes before injection of $250 \mathrm{MBq}$ to $500 \mathrm{MBq}$ of ${ }^{99 \mathrm{~m}} \mathrm{Tc}$-exametazime. During the injection, subjects were lying comfortably on the imaging table with eyes covered and ears unplugged, and environmental noises were kept to a minimum for five minutes after the start of the injection. Before acquiring the image, subjects were positioned with the aid of crossed light beams and external markers so that slices of brain were acquired parallel to the orbitomeatal plane. The head was fixed lightly with pressure pads over the zygomatic arches during the whole scan, and position was checked intermittently. This method allows for reliable replication of tracer uptake measurements. ${ }^{34}$ At least eight transaxial slices parallel to the orbitomeatal plane were acquired. For the present study, three non-overlapping transaxial slices, one at the midventricular level, the second about 2 $\mathrm{cm}$ above, and a third $4 \mathrm{~cm}$ above the first were available for all subjects and were, therefore, selected for analysis.

For the quantitative analysis of uptake patterns, templates were drawn from a standard brain atlas. ${ }^{41}$ These templates were symmetrically and linearly deformed to fit the outline of the brain defined by the $40 \%$ isocontour line of each slice. ${ }^{34}$ This changed the size and shape of the overall template, leaving the relative relation of regions of interest to each other intact. It has the disadvantage of not taking account of individual variations in anatomy but it provides an objective and reliable method of determining relative uptake patterns. The fitting of the template and the scan analysis were performed by a trained technician who was unaware of the diagnosis and naive as to any anticipated group differences. Regional count densities were transferred from the imaging programme (SME 810 software version $2 \cdot 61$ ) and analysed with SPSS for the Apple Macintosh (version 4.0). Regional count densities were normalised by

Table 1 Descriptive variables for the five original subject groups

\begin{tabular}{|c|c|c|c|c|c|}
\hline \multirow[b]{2}{*}{ Variable } & \multicolumn{5}{|l|}{ Group } \\
\hline & $\begin{array}{l}\text { Controls } \\
(n=20)\end{array}$ & $\begin{array}{l}\text { Schizo- } \\
\text { affective and } \\
\text { other psychoses } \\
\text { no drugs } \\
(n=10)\end{array}$ & $\begin{array}{l}\text { Schizophrenia } \\
\text { actively } \\
\text { psychotic } \\
\text { no drugs } \\
(n=20)\end{array}$ & $\begin{array}{l}\text { Schizophrenia } \\
\text { good drug } \\
\text { response } \\
(n=20)\end{array}$ & $\begin{array}{l}\text { Schizophrenia } \\
\text { poor drug } \\
\text { response } \\
(n=20)\end{array}$ \\
\hline Age & $33.5(22 \cdot 0)$ & $22.5(13.3)$ & $32 \cdot 5(16 \cdot 8)$ & $33.5(20.5)$ & $33.5(16.0$ \\
\hline Sex (male/female) & $8 / 12$ & $9 / 1$ & $12 / 8$ & $10 / 10$ & $10 / 10$ \\
\hline Handedness & $2 / 18$ & $1 / 9$ & $3 / 17$ & $2 / 18$ & $2 / 18$ \\
\hline $\begin{array}{l}\text { (leturngnt) } \\
\text { NART predicted IO }\end{array}$ & $113.5(18.0)$ & $118.0(11 \cdot 5)$ & $104 \cdot 0(28 \cdot 0)$ & $117 \cdot 0(20 \cdot 0)$ & $89.0(18.0)$ \\
\hline Duration of illness & - & $1.0(4 \cdot 0)$ & $7 \cdot 5(9 \cdot 8)$ & $7 \cdot 5(15 \cdot 3)$ & $10.0(17 \cdot 0)$ \\
\hline CPZ units & - & - & - & $137.5(322.5)$ & $950.0(1112.5)$ \\
\hline
\end{tabular}

Data for sex and handedness are numbers of patients; other variables are medians (interquartile ranges).

CPZ units = chlorpromazine units. 
Figure 1 Side view of the three imaging planes, 4,6 , and $8 \mathrm{~cm}$ above the orbitomeatal line. Frontal regions of interest and occipital reference regions have been shaded.

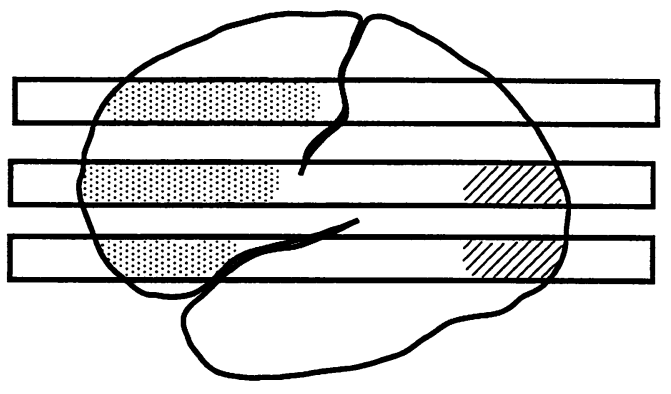

Unmedicated actively psychotic non-schizophrenic patients $v$ controls
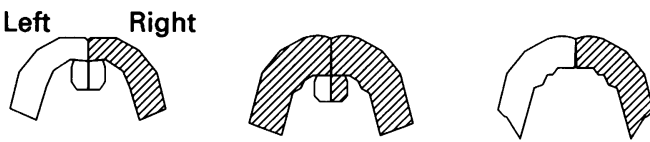

Unmedicated actively psychotic schizophrenic patients $v$ controls
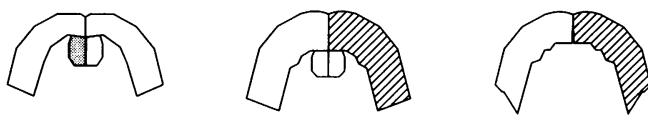

division by an area weighted mean of posterior brain regions of interest (fig 1). This method was preferred to a whole brain normalisation because the study was to focus on anterior brain structures; if these structures had been included in the reference area, any effects would, of course, be diminished. The occipital cortex was chosen because the visual stimulus conditions of all subjects were controlled for during the time of injection. The cerebellum was not used as a reference area, because the objective fitting of regions of interest provides particular difficulties with this structure, and normal tracer uptake cannot be assumed in all patients, particularly if they were treated with drugs for some time. ${ }^{42}$ Finally, region of interest analysis was preferred to pixel by pixel analysis because previous published work has averaged activity over large areas, and pixel by pixel studies have not shown highly localised frontal changes in schizophrenia. ${ }^{43}$

We used planned comparisons for the frontal and anterior cingulate regions of interest where abnormalities were predicted from the medical literature. Mann-Whitney $U$ tests were used for a comparison of patient groups and controls in the four anterior cingulate and six frontal regions of interest. No adjustment was made for multiple testing as all comparisons that were carried out were planned. ${ }^{44}$ The two groups of schizophrenic patients treated with drugs were combined, because there was no a priori hypothesis about the effect of treatment responsiveness on anterior tracer uptake.
Medicated schizophrenic patients $v$ controls

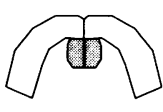

$+4 \mathrm{~cm}$

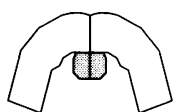

$+6 \mathrm{~cm}$

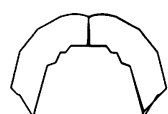

$+8 \mathrm{~cm}$
Figure 2 Planned comparisons betwen patient groups and controls in anterior regions of interest with the MannWhitney $U$ test. Hatched areas indicate excess uptake in patients, stippled areas reduced uptake, both with twotailed $P$ values $<0.05$.

\section{Results}

Table 1 gives the age, sex, handedness, IQ predicted by the National Adult Reading Test $\left(\right.$ NART $\left.^{45}\right)$, as well as duration of illness and drugs in chlorpromazine units. The patients with schizophrenia were well matched with controls for age and sex. The non-schizophrenic psychotic patients were younger and had an excess of male patients compared with schizophrenia and control groups. Premorbid intelligence as estimated by the NART was lower for actively psychotic patients and schizophrenic patients with a poor response to drugs. The relevance of this finding may be related to illness factors rather than simply to premorbid ability. As expected, patients taking drugs had a longer duration of illness than the non-schizophrenic patients or the drug free schizophrenic groups.

Table 2 and fig 2 give the results of the planned group comparisons between patient groups and healthy volunteers for anterior

Table 2 Occipital ratios for anterior unilateral regions of interest in four samples.

\begin{tabular}{|c|c|c|c|c|}
\hline \multirow[b]{2}{*}{ Region of interest } & \multicolumn{4}{|l|}{ Group } \\
\hline & $\begin{array}{l}\text { Controls } \\
(n=20)\end{array}$ & $\begin{array}{l}\text { Schizo- } \\
\text { affective and } \\
\text { other psychoses } \\
\text { no drugs } \\
(n=10)\end{array}$ & $\begin{array}{l}\text { Schizophrenia } \\
\text { no drugs } \\
(n=20)\end{array}$ & $\begin{array}{l}\text { Schizophrenia } \\
\text { treated with drugs } \\
n=40)\end{array}$ \\
\hline Left anterior cingulate & $1.09(0.09)$ & $1 \cdot 13(0 \cdot 13)$ & $1.02(0.17)^{\star}$ & $0.98(0.12)^{\star}$ \\
\hline Left anterior cingulate (6) & $1 \cdot 11(0 \cdot 11)$ & $1.12(0.12)$ & $1 \cdot 12(0 \cdot 18)$ & $1.03(0.11)^{\star}$ \\
\hline Left frontal & $0.95(0.08)$ & $0.99(0.10)$ & $0.97(0.08)$ & $0.92(0.08)$ \\
\hline Left frontal (6) & $0.92(0.08)$ & $0.97(0.09)^{\star}$ & $0.95(0.08)$ & $0.91(0.10)$ \\
\hline Left frontal (8) & $0.89(0.06)$ & $0.92(0.09)$ & $0.92(0.12)$ & $0.85(0.08)$ \\
\hline Right anterior cingulate & $1.08(0 \cdot 10)$ & $1 \cdot 12(0 \cdot 16)$ & $1.05(0.15)$ & $1.04(0.11)^{\star}$ \\
\hline Right anterior cingulate (6) & $1.13(0.09)$ & $1.18(0.08)^{\star}$ & $1 \cdot 11(0 \cdot 10)$ & $1.03(0.08)^{\star}$ \\
\hline Right frontal & $0.96(0.05)$ & $1.02(0.07)^{\star}$ & $0.98(0.06)$ & $0.95(0.07)$ \\
\hline Right frontal (6) & $0.94(0.06)$ & $0.97(0.09)^{\star}$ & $0.97(0.07)^{\star}$ & $0.93(0.09)$ \\
\hline Right frontal (8) & $0.89(0.05)$ & $0.93(0.08)^{\star}$ & $0.93(0.10)^{\star}$ & $0.87(0.09)$ \\
\hline
\end{tabular}


regions of interest. Non-schizophrenic psychotic patients not given drugs showed increased tracer uptake in most prefrontal regions of interest, particularly on the right side (fig 2A). Schizophrenic patients not treated with drugs showed similar hyperfrontality, pronounced on the right side and in the upper two slices, combined with reduced uptake in the left inferior cingulate cortex (fig 2B). Schizophrenic patients treated with drugs showed reductions in frontal areas but these were too small to reach significance. Significant reductions in tracer uptake were seen only in mesial frontal areas (fig $2 \mathrm{C}$ ). The expected hypofrontality in the prefrontal cortex was, therefore, not discernible in this large sample of 40 patients taking drugs. There were no significant correlations between symptom scores or dose of drug and anterior regional tracer uptake in the treated group.

\section{Discussion}

Our patients taking drugs showed a reduction in tracer uptake to the mesial frontal-anterior cingulate regions of cerebral cortex. The central finding of this study is, therefore, the dissociation of activity between prefrontal and anterior cingulate structures at rest in psychoses and schizophrenia. Hypofrontality, confined to the anterior cingulate, could also be found in acutely ill patients with DSM-III$\mathrm{R}$ schizophrenia and schizophreniform disorder but not treated with drugs, thereby replicating the results of Tamminga and coworkers. ${ }^{36} \mathrm{By}$ contrast, the prefrontal cortex, the traditional locus of hypofrontality, was overactive in psychotic and schizophrenic patients not given drug treatment, with small non-significant reductions in schizophrenic patients taking drugs.

Global or prefrontal hypofrontality is, therefore, not the robust finding at rest that it is often taken to be in chronic schizophrenia. The common denominator for a diagnosis of schizophrenia instead seems to be a reduction of tracer uptake localised to the mesial frontal and anterior cingulate cortex. It is difficult at present to assess the functional relevance of this underactivity. Pardo et $a l^{46}$ have associated anterior cingulate activation in normal volunteers with performance in the Stroop task, a verbal-visual attention task performed poorly by schizophrenic patients. ${ }^{47}$ Furthermore, we have previously examined a patient presenting with right unilateral auditory hallucinations with delusional elaboration in the presence of right hearing impairment and tinnitus with a localised right unilateral anterior cingulate reduction of tracer uptake $(\mathrm{AB}$ Doris, RE O'Carroll, KP Ebmeier, unpublished data). The localised reduction in mesial frontal activity can be interpreted, after Frith and Done, ${ }^{48}$ as reflecting a disruption at a nodal point in the brain monitoring system involved in the supervision of willed actions, that could arguably be the correlate of psychotic experiences in schizophrenia. It is likely not to be the only possible mechanism involved in the generation of psychotic experi- ences, because the non-schizophrenic patients showed, if anything, cingulate overactivity.

It cannot be entirely excluded that drugs played a part in the anterior reduction of tracer uptake in the treated group, although there were no correlations with dose. It is also impossible to claim primacy for medial frontal involvement in schizophrenia, because this area is closely linked with limbic cortex, prefrontal cortex, and subcortical structures such as the thalamus.

What then is the status of generalised hypofrontality in schizophrenia? Weinberger ${ }^{20}$ has argued that the failure of resting studies to control for the mental activity of subjects during tracer uptake or wash out is responsible for contradictory results. This explanation is consistent with the recent finding that symptom patterns or syndromes at the time of study are associated with specific regional patterns of resting perfusion-for example, negative symptoms or psychomotor poverty with reduced prefrontal uptake. ${ }^{1943}$ It might also explain why hyperfrontality in schizophrenic patients has only been described in resting, albeit, actively psychotic patients. ${ }^{15-19}$ The association of psychomotor impairment with

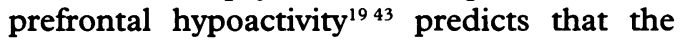
extent of hypofrontality is related to patient selection. The original findings with xenon133 were on extremely retarded, in some cases mute, patients. There was, however, no convincing relation between prefrontal perfusion and psychomotor poverty in our patients treated with drugs. This implies that other factors have contributed to the hypofrontality of other samples. One possibility is that older patients and patients with more severe cognitive deficits may show disproportionate frontal deficits. ${ }^{49}$ The complexity of the syndrome we call schizophrenia means that few studies present or control for all the details relevant to the clinical state of different patient groups. The challenge is to isolate those components of the schizophrenia syndrome that can be related reliably to abnormal patterns of brain function: the idea that hypofrontality is a central pathophysiological abnormality in schizophrenia does not help us to meet it. We thank the Wellcome Trust and the Scottish Home and
Health Department for financial support, Nadine Dougall for Health Department for financial support, Nadine Dougall for
technical assistance, in particular in the development of the templates and their fitting, Catherine Murray for her skilful and sympathetic supervision of patients, and Norma Brearley for the careful preparation of the manuscript.

1 Ingvar DH, Franzen G. Abnormalities of cerebral blood flow distribution in patients with chronic schizophrenia. Acta Psychiatr Scand 1974;50:425-62.

2 Andreasen NC, Rezai K, Alliger R, Swayze VW, Flaum M, Kirchner $\mathrm{P}$, et al. Hypofrontality in neuroleptic-naive patients and in patients with chronic schizophrenia. Arch Gen Psychiatry 1992;49:943-58.

3 Buchsbaum MS, Ingvar DH, Kessler R, Waters RN, Cappelletti J, van Kammen DP, et al. Cerebral glucography with positron tomography. Use in normal subjects and in patients

4 Brodie JD, Christman DR, Corona JF, Fowler JS, GomezMont F, Jaeger J, et al. Patterns of metabolic activity in the treatment of schizophrenia. Ann Neurol 1984;15: S166-9.

5 Farkas T, Wolf AP, Jaeger J, Brodie JD, Christman DR, Fowler JS. Regional brain glucose metabolism in chronic schizophrenia. A positron emission transaxial tomographic study. Arch Gen Psychiatry 1984;41: 293-300.

6 DeLisi LE, Buchsbaum MS, Holcomb HH, Dowling- 
Zimmerman S, Pickar D, Boronow J, et al. Clinical correlates of decreased anteroposterior metabolic gradients in positron emission tomography (PET) of schizophrenic patients. Am $f$ Psychiatry 1985;142:78-81.

7 Wolkin A, Jaeger J, Brodie JD, Wolf AP, Fowler J, Rotrosen J, et al. Persistence of cerebral metabolic abnormalities in chronic schizophrenia as determined by positron emission tomography. Am $f$ Psychiatry 1985; positron em

8 Lewis SW, Ford RA, Syed GM, Reveley AM, Toone BU. A controlled study of Tc-99m-HMPAO single-photon emission imaging in chronic schizophrenia. Psychol Med 1992;22:27-35.

9 Widen L, Blomqvist G, Greitz T, Litton JE, Bergstrom M, Ehrin E, et al. PET studies of glucose metabolism in patients with schizophrenia. Am F Neuroradiol 1983;4: 550-2.

10 Sheppard G, Manchanda R, Gruzelier J, Hirsch SR, Wise $R$, Frackowiak R, Jones T. 15-O positron emission tomographic scanning in predominantly never-treated acute schizophrenic patients. Lancet 1983;ii:1448-52.

11 Gur RE, Skolnick BE, Gur RC, Caroff S, Rieger W, Obrist WD, et al. Brain function in psychiatric disorders: I. Arch Gen Psychiatry 1983;40:1250-4.

12 Gur RE, Gur RC, Skolnick BE, Caroff S, Obrist WD, Resnick S, Reivich M. Brain function in psychiatric dis-
orders. III. Regional cerebral blood flow in unmedicated orders. III. Regional cerebral blood flow in unmedica

13 Gur RE, Resnick SM, Alavi A, Gur RC, Caroff S, Dann R et al. Regional brain function in schizophrenia. Arch Gen Psychiatry 1987;44:119-25.

14 Gur RE, Resnick SM, Gur RC. Laterality and frontality of cerebral blood flow and metabolism in schizophrenia: relationship to symptom specificity. Psychiatry Res 1989 27:325-34.

15 Volkow ND, Brodie JD, Wolf AP, Angrist B, Russell J, Cancro R. Brain metabolism in patients with schizophrenia before and after acute neuroleptic administration. $¥$ Neurol Neurosurg Psychiatry 1986;49:1 199-202.

16 Wiesel FA, Wik G, Sjögren I, Blomqvist G, Greitz T, Stone-Elander $S$. Regional brain glucose metabolism in drug free schizophrenic patients and clinical correlates. Acta Psychiatr Scand 1987;76:628-41.

17 Szechtman H, Nahmias C, Garnett ES, Firnau G, Brown GM, Kaplan R, Cleghorn JM. Effect of neuroleptics on altered cerebral glucose metabolism in schizophrenia. Arch Gen Psychiatry 1988;45:523-32.

18 Cleghorn JM, Garnett ES, Nahmias C, Firnau G, Brown $\mathrm{GM}$, Kaplan $\mathrm{R}$, et al. Increased frontal and reduced parietal glucose metabolism in acute untreated schizophrenia. Psychiatry Res 1989;28:119-33.

19 Ebmeier KP, Blackwood DHR, Murray C, Souza V, Walker M, Dougall N, et al. Single photon emission computed tomography with $99 \mathrm{~m}$ Tc-exametazime in unmedicated schizophrenic patients. Biol Psychiatry 1993;33:487-95.

20 Weinberger DR. Schizophrenia and the frontal lobe. Trends Neurosci 1988;11:367-70.

21 Andersen AR, Friberg H, Lassen NA, Kristensen $K$ Neirinckx RD. Serial studies of cerebral blood flow using ${ }^{99 m}$ Tc-HMPAO: a comparison with ${ }^{133 \mathrm{Xe} \text {. Nucl }}$ Med Commun 1987;8:549.

22 Yonekura Y, Nishizawa S, Mukai T, Fujita T, Fukuyam $\mathrm{H}$, Iokikawa $M$, et al. SPECT with Tc-HMPAO compared with regional cerebral blood flow measured by PET: effects of linearisation. $\mathcal{F}$ Cereb Blood Flow Metab 1988;8:S82-9.

23 Inugami A, Kanno I, Uemura K, Shishido F, Murakami $\mathrm{M}$, Tomura $\mathrm{N}$, et al. Linearisation correction of Tclabelled HMPAO image in terms of regional CBF distribution: comparison to $\mathrm{C}^{15} \mathrm{O}_{2}$ inhalation steady state method measured by positron emission tomography. method measured by positron emission

24 Gemmell HG, Evans NTS, Besson JAO, Roeda D Davidson J, Dodd MG, et al. Regional cerebral blood flow imaging: a quantitative comparison of technetium$99 \mathrm{~m}$-HMPAO SPECT with $\mathrm{C}^{15} \mathrm{O}_{2}$ PET. $f \mathrm{Nucl} \mathrm{Med}$ 1990;31:1595-1600

25 Heiss W-D, Herholz K, Podreka I, Neubauer I, Pietrzyk U. Comparison of [ ${ }^{99 \mathrm{~m} T c] H M P A O}$ SPECT with $\left[{ }^{18} \mathrm{~F}\right]$ fluoromethane PET in cerebrovascular disease. $f$ Cereb Blood Flow Metab 1990;10:687-97.

26 Pupi A, Bisi G, Sciagra R, Santoro G, De Cristofaro MTR, Formiconi AR, Meldolesi U. The comparison of brain distribution of HMPAO and microspheres in humans. F Cereb Blood Flow Metab 1989;9:S411.

27 Woods SW, Hegeman IM, Zubal IG, Krystal JH, Koster $\mathrm{K}$, Smith EO, et al. Visual stimulation increases technetium-99m-HMPAO distribution in human visual cortex. $¥$ Nucl Med 1991;32:210-4.
28 Ebmeier KP, Murray CL, Dougall NJ, O'Carroll RE, Goodwin GM. Unilateral voluntary hand movement and regional cerebral uptake of technetium-99m-exametazime in human control subjects. $\mathcal{F}$ Nucl Med 1992;33: 1623-7.

29 Shedlack KJ, Hunter R, Wyper D, McLuskie R, Fink G, Goodwin GM. The pattern of cerebral activity underlying verbal fluency shown by split-dose single photon emisvion tomography (SPET or SPECT) in normal volunsion tomography (SPET or SPECT)

30 Rubin P, Holm S, Friberg L, Videbech P, Anderson HS, Bendsen BB, et al. Altered modulation of prefrontal and subcortical brain activity in newly diagnosed schizophrenia and schizophreniform disorder. Arch Gen Psychiatry 1991;48:987-95.

31 Hunter R, Wyper DJ, Patterson J, Hansen MT, Goodwin GM. Cerebral pharmacodynamics of physostigmine in SPET imaging. Br $\mathcal{F}$ Psychiatry 1991;158:351-7.

32 Ebmeier KP, Hunter R, Curran SM, Dougall NJ, Murray CL, Wyper DJ, et al. Effects of a single dose of the acetylcholinesterase inhibitor velnacrine on recognition memory and regional cerebral blood flow in Alzheimer's disease. Psychopharmacology 1992;108:103-9.

33 Moffoot A, O'Carroll RE, Murray C, Dougall N, Ebmeier $\mathrm{K}$, Goodwin GM. Clonidine infusion increases uptake of $\mathrm{K}$, Goodwin GM. Clonidine infusion increases uptake of Korsakoff's psychosis. Psychol Med 1993;24:53-61.

34 Ebmeier KP, Dougall NJ, Austin M-P, Murray CL Curran SM, O'Carroll R, et al. The split-dose technique for the study of psychological and pharmacological activation with the cerebral blood flow marker exametazim and single photon emission computed tomography (SPECT): reproducibility and rater reliability. International

35 Kawasaki Y, Suzuki M, Maeda Y, Urata K, Yamaguchi N, Matsuda $\mathrm{H}$, et al. Regional cerebral blood flow in patients with schizophrenia. A preliminary report. Eur patients with schizophrenia. A preliminary rep

36 Tamminga CA Thaker GK, Buchanan R, Kirkpatrick B, Alphs LD, Chase TN, Carpenter WT. Limbic system Alphs LD, Chase TN, Carpenter WT. Limbic system emission tomography with fluorodeoxyglucose and neoemission tomography with fluorodeoxyglucose and neocortical alterations with defich

37 Siegel BV Jr, Buchsbaum MS, Bunney WE Jr, Gottschalk LA, Haier RJ, Lohr JB, et al. Cortical-striatal-thalamic circuits and brain glucose metabolic activity in 70 unmedicated male schizophrenic patients. $\mathrm{Am}$ Psychiatry 1993;150:1325-36.

38 American Psychiatric Association. Diagnostic and statistical manual of mental disorders. 3rd ed, revised. Washington, DC: American Psychiatric Association, 1987.

39 May PRA, Dencker SJ, Hubbard JW, Midha KK, Liberman RP. A systematic approach to treatment resistance in schizophrenic disorders. In: Dencker SJ tance in schizophrenic disorders. In: Dencker SJ, Kulhanek F, ed. Treatment resistance in schizoph

40 Krawiecka $M$, Goldberg D, Vaughan $M$. A standardized psychiatric assessment scale for rating chronic psychotic patients. Acta Psychiatricr Scand 1977;55:299-308.

41 Talairach J, Zilkha G, Tournoux P, Prosalentis A, BordasFerrier M, Covello L, et al. Atlas d'anatomie stereotactique du telencephale. Paris: Masson, 1988.

42 Heath RG, Franklin DE, Shraberg D. Gross pathology of the cerebellum in patients diagnosed and treated as functional psychiatric disorders. F Nerv Ment Dis 1979, 167:585-92.

43 Liddle PF, Friston KJ, Frith CD, Hirsch SR, Jones T, Frackowiak RSJ. Patterns of cerebral blood flow in schizophrenia. Br f Psychiatry 1992;160:179-86.

44 Keppel G, Zedeck S. Data analysis for research designs. New York: Freeman, 1989

45 Nelson HE. National adult reading test (NART): test manual. Windsor: NFER-Nelson, 1982.

46 Pardo JV, Pardo PJ, Janer KW, Raichle ME. The anterior cingulate cortex mediates processing selection in the Stroop attentional conflict paradigm. Proc Natl Acad $S c$ USA 1990;8:256-9.

47 Liddle PF, Morris DL. Schizophrenic syndromes and frontal lobe performance. $\mathrm{Br} \mathcal{F}$ Psychiatry 1991;158 340-5

48 Frith CD, Done DJ. Towards a neuropsychology of schizophrenia. Br f Psychiatry 1988;153:437-43.

49 Paulman RG, Devous MD Sr, Gregory RR, Herman JH, Jennings L, Bonte FJ, et al. Hypofrontality and cognitive impairment in schizophrenia: dynamic single-photon tomography and neuropsychological assessment of schizophrenic brain function. Biol Psychiatry 1990;27: 377-99. 